\title{
Massive spontaneous hemorrhage in giant type 1 neurofibromatosis in soft tissue of chest wall
}

\author{
Kewei Zhang, MD, PhD, ${ }^{\mathrm{a}}$ Jena Song, MS, ${ }^{\mathrm{b}}$ Wenji Xiong, MD, PhD, ${ }^{\mathrm{c}} \mathrm{Zhi} \mathrm{Li}, \mathrm{PhD},{ }^{\mathrm{a}}$ Dianbo Cao, MD, PhD, \\ Tianbo Jiang, HS, ${ }^{b}$ and Wei Liu, MD, PhD, ${ }^{a}$ Changchun, China, and New York, NY
}

Type 1 neurofibromatosis (NF1), previously known as von Recklinghausen disease, is a single genetic disorder characterized by neurofibromas and hyperpigmented skin lesions. ${ }^{1}$ The clinical manifestations of NF1 are extremely variable. Vascular involvement, although rarely encountered, can cause fatal spontaneous hemorrhage. ${ }^{2}$ The following describes a rare case of giant NF1 in the soft tissue of the chest wall presenting with massive spontaneous hemorrhage.

\section{CLINICAL SUMMARY}

A 20-year-old man with a 16-year history of NF1 was admitted to the hospital on an emergency basis with spontaneous hemorrhage quickly growing inside a giant neurofibroma in the wall of the chest on the left side. On physical examination, the patient was of short stature and displayed diffused café-au-lait maculae on the skin, plexiform neurofibroma on the left chest wall, scoliosis, and freckling in the axilla and groin. There was a $25 \times 25 \times 20$-cm hematoma with a $20 \times 20 \times 15-\mathrm{cm}$ neurofibroma originating from the left posterior chest

From the Department of Thoracic Surgery, ${ }^{\mathrm{a}}$ Bethune First Hospital of Jilin University, Changchun, China; Department of Pathology, ${ }^{\mathrm{b}}$ Mount Sinai School of Medicine, New York, NY; and the Department of Radiology, ${ }^{\mathrm{c}}$ Bethune First Hospital of Jilin University, Changchun, China.

Disclosures: Authors have nothing to disclose with regard to commercial support.

Received for publication March 16, 2012; revisions received April 16, 2012; accepted for publication May 16, 2012; available ahead of print July 16, 2012.

Address for reprints: Wei Liu, MD, PhD, Department of Thoracic Surgery, Bethune

First Hospital of Jilin University, No. 71 Xinmin St, 130021, Changchun, China

(E-mail: davidliuw@ hotmail.com).

J Thorac Cardiovasc Surg 2012;144:e92-3

$0022-5223 / \$ 36.00$

Copyright (c) 2012 by The American Association for Thoracic Surgery

http://dx.doi.org/10.1016/j.jtcvs.2012.05.046 wall, which covered from the left scapula down to the 12th rib. The patient also had sinus tachycardia and hypotension. Digital subtraction angiography (DSA) revealed 3 large arteries ( 2 from the 12th and 11th intercostal arteries and 1 from the first vertebral artery) feeding the hematoma and tumor (shown in Figure 1, $A$ and $B$ ). Blood counts showed a progressive decrease of red blood cell and hemoglobin levels (from $3.96 \times 10^{12} / \mathrm{L}$ to $2.65 \times 10^{12} / \mathrm{L}$ and from $119 \mathrm{~g} / \mathrm{L}$ to $78 \mathrm{~g} / \mathrm{L}$, respectively). Emergency angiographic subcutaneous embolization was initially performed to stop the bleeding, and the patient's hemodynamic condition quickly stabilized. On the seventh day after embolization, the hematoma and neurofibroma were resected smoothly with $150 \mathrm{~mL}$ of intraoperative blood loss. Histologic examination confirmed the former diagnosis. The patient was discharged uneventfully 12 days after the operation. There was no recurrence of neurofibroma or hematoma at 12-month follow-up.

\section{DISCUSSION}

Vascular involvement is one of the various complications of NF1, and its incidence has been reported to be only $3.6 \%{ }^{2}$ Vasculopathy can range from large vessels in visceral organs to minute vessels in soft tissue and can produce vascular stenosis, occlusion, aneurysm, pseudoaneurysm, rupture, or arteriovenous fistula. It is considered one of the most important causes of early death in individuals with NF1 because it can cause massive spontaneous hemorrhage. ${ }^{3}$ Only 2 cases of NF1 have been reported for massive spontaneous hemorrhage in the chest wall soft tissue, and the treatment strategies used were absolutely different from each other. In the report by Lessard, Izadpanah, and

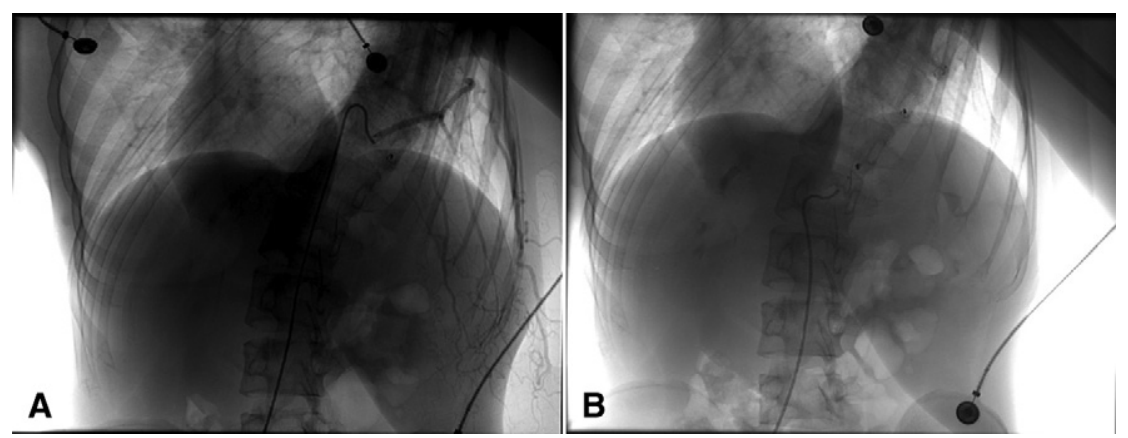

FIGURE 1. A, Digital subtraction angiography showed that a tumor feeding artery originated from the 12th intercostal artery, which was tortuous within the mass. B, Digital subtraction angiography showed the shadow of 3 coils that occluded proximal feeding arteries of tumor after embolization. 
Williams, ${ }^{4}$ angiographic studies were adopted and showed that the bleeding emerged from multiple sites, the major supplying vessels were then embolized, and the tumor was smoothly resected 3 days after embolization. However, in the case reported by Rao, Affifi, and Ghazarian, ${ }^{5}$ the patient was operated on without angiography, there was no single bleeding source and vascular abnormality identified intraoperatively, and surgical debridement and hemostasis were performed multiple times over the course of 26 days.

Such spontaneous hemorrhage is always insidious and minute with no apparent cause when it first begins. The diagnosis is often delayed, and the patients are in unavoidable and unstable hemodynamic status when they arrive at the hospital. Consequently, for emergency management, besides basic life support and the exclusion of coagulation abnormalities, the identification of the bleeding source should be the primary concern. Angiography coupled with subcutaneous embolization under DSA is a prompt, minimally invasive method for finding and controlling the bleeding vessels simultaneously, and it creates the possibility and enough preparation for later surgical intervention. One possible management strategy might be to consider routine surveillance of vascular lesions by angiography in patients with NF1, because it may be helpful in detecting and handling abnormal vessels earlier and thus prevent possible spontaneous hemorrhage.

Embolization is used to find the supplying vessels and control bleeding temporarily, but it cannot replace surgery. Although surgery is more aggressive and complicated owing to vessel fragility, it has a unique role in such cases: (1) it may be the only way and the best option for the permanent control of the ongoing or potential spontaneous hemorrhage; (2) early surgical resection of a huge tumor may reduce the possibility of malignant degeneration and of secondary skin necrosis and ulcerations caused by local malnutrition; and (3) surgery also has the potential for considerable positive cosmetic and pulmonary physiology impact. However, it is impossible to surgically remove all neurofibromas, which may affect virtually every nerve within the chest wall.

In conclusion, massive spontaneous hemorrhage in the soft tissue of the chest wall is very uncommon in patients with NF1. This case shows that angiography and embolization under DSA accompanied by surgery have great potential in the diagnosis and control of massive hemorrhage for patients with NF1.

We express our appreciation to Dr Jean Deslauriers (from Laval University, Canada) for his help in reviewing this case report.

\section{References}

1. Neurofibromatosis. Conference statement. National Institutes of Health Consen sus Development Conference. Arch Neurol. 1988;45:575-8.

2. Conlon NP, Redmond KC, Celi LA. Spontaneous hemothorax in a patient with neurofibromatosis type 1 and undiagnosed pheochromocytoma. Ann Thorac Surg. 2007;84:1021-3

3. Jett K, Friedman JM. Clinical and genetic aspects of neurofibromatosis 1. Genet Med. 2010;12:1-11.

4. Lessard L, Izadpanah A, Williams HB. Giant thoracic neurofibromatosis type 1 with massive intratumoral haemorrhage: a case report. J Plast Reconstr Aesthet Surg. 2009;62:e325-9.

5. Rao V, Affifi RA, Ghazarian D. Massive subcutaneous hemorrhage in a chest-wal neurofibroma. Can J Surg. 2000;43:459-60.

\title{
True aneurysm of anterior mitral leaflet-A rare entity
}

\author{
Trushar P. Gajjar, DNB, and Neelam B. Desai, MCh, DNB, Andhra Pradesh, India
}

True aneurysms, or diverticula, of the mitral valve are rare. $^{1,2}$ They are most common in patients with infective endocarditis affecting the aortic valve, but they can also present with chronic mitral regurgitation or as a complication of mitral valve prolapse. ${ }^{1,2}$ We present

\footnotetext{
From the Sri SathyaSai Institute of Higher Medical Sciences, Prasanthigram, District Anantapur, Andhra Pradesh, India.

Disclosures: Authors have nothing to disclose with regard to commercial support.

Received for publication March 23, 2012; revisions received April 20, 2012; accepted for publication May 16, 2012; available ahead of print June 18, 2012.

Address for reprints: Trushar P. Gajjar, DNB, Sri SathyaSai Institute of Higher Medical Sciences, Prasanthigram, District Anantapur, Andhra Pradesh 515134, India (E-mail: trushargajjar@gmail.com).

J Thorac Cardiovasc Surg 2012;144:e93-5

$0022-5223 / \$ 36.00$

Copyright (c) 2012 by The American Association for Thoracic Surgery

http://dx.doi.org/10.1016/j.jtcvs.2012.05.055
}

a case of true aneurysm of anterior mitral leaflet causing mitral regurgitation and describes the pathogenesis, diagnostic modalities, and surgical decision with a review of the published data.

\section{CASE REPORT}

A 39-year-old man presented with palpitation and breathlessness on exertion, New York Health Association class II. Physical examination revealed a pansystolic murmur at the apex radiating posteriorly up to the midscapular line. Chest radiography showed a cardiothoracic ratio of $60 \%$ to $65 \%$ and pulmonary hilar congestion. The electrocardiogram showed sinus rhythm, normal axis, and left ventricular hypertrophy. The transthoracic and transesophageal echocardiogram showed an aneurysm of the anterior mitral leaflet 